адресанта. Більшість фраз нерозуміння вимовляють у нормальному темпі. Прискорений темп властивий у найбільшій мірі фразам прямого нерозуміння, уповільнення темпу властиве тільки фразам прямого нерозуміння й удаваного нерозуміння. Крім того, за даними аудиторського аналізу, деяким висловлюванням у нормальному та прискореному темпі властиві прагматичні паузи, що мають місце перед лексемою, яка експлікує нерозуміння.

Ключові слова: нерозуміння, інтонація, тональний рівень, тональний діапазон, гучність, темп.

Ganna A. OLIINYK,

Teacher, English Language Chair Nr 3, National University "Odessa Maritime Academy", 8 Didrikhson Str., Odessa, 65029, Ukraine; tel.: +38(048) 7332334 ;

e-mail: oliinyk.ha@gmail.com; ORCID ID: 0000-0002-8840-3140

\title{
INTONATION MEANS OF EXPRESSING MISUNDERSTANDING IN ENGLISH FILM DISCOURSE
}

Summary. The immediate purpose of the paper is to provide intonation differentiation of the three types of misunderstanding in dialogue communication. The object of analysis is the English artistic discourse. The subject of investigation is the intonation means of expressing misunderstanding in English Film Discourse. The investigation results in identifying the common and differentiating intonation means of expressing direct misunderstanding, pretended misunderstanding and pretended understanding. The investigation of actors' intonation has enabled the author to establish the certain misunderstanding phrases intonation characteristics: tone level, tone range, intensity and tempo. Conclusions. In terms of the tone level and tone range, most utterances have turned out to have mid pitch level and mid tone range. The more emotional the speaker is, the wider his voice range seems to, especially when it comes to pretended misunderstanding. In terms of intensity, most phrases are characteristic of normal intensity. The investigation of tempo in the phrases of misunderstanding has confirmed its changeable and unstable character, presupposed by the addresser's sincerity / insincerity. Most misunderstanding phrases are pronounced with a normal tempo. The accelerated tempo is common both for the phrases of direct misunderstanding and pretended misunderstanding. Another registered tendency concerns pragmatic pauses, which take place right in front of the lexical units, expressing misunderstanding.

Key words: misunderstanding, intonation, pitch level, voice range, intensity, tempo.

Статтю отримано 9.09.2017 p.

http://dx.doi.org/10.18524/2307-4558.2017.28.115856

УДК 811.161.1’367:659.123(477)

\section{СОБЧЕНКО Наталия Сергеевна,}

старший преподаватель кафедры русского языка Одесского национального университета имени И. И. Мечникова; Французский бульвар, 24/26, г. Одесса, 65058, Украина; тел.: +38 0679461358 ;

e-mail: ecoletk17@ukr.net; ORCID ID: 0000-0002-1382-5058

\section{ПРИЁМЫ СИНТАКСИЧЕСКОЙ ИГРЫ В РЕКЛАМНОМ ДИСКУРСЕ УКРАИНЫ}

Аннотация. Цель статьи - рассмотреть приёмы создания языковой игры в рекламном дискурсе на синтаксическом уровне. Объект исследования - номинационная деятельность в рекламном дискурсе. Предмет исследования - приёмы создания языковой игры на синтаксическом уровне. В статье использованы следующие методы: описательный, количественный, метод компонентного анализа. Результат исследования: названы основные приёмы языковой игры на синтаксическом уровне и подробно рассмотрен приём синтаксического повтора. Определена основная функция использования языковой игры на синтаксическом уровне в рекламном тексте. Выводы. Игра на синтаксическом уровне является яркой составляющей многих рекламных текстов. Чаще всего в рекламном тексте используются следующие синтаксические приёмы языковой игры: парцелляция, предикативная односоставность, повтор, антитеза, неполнота высказывания. Наиболее частотным является повтор, который включает в себя анафору, эпифору, анадиплосис, рамочную конструкцию и полисиндетон. Практическое применение результатов исследования могут способствовать дальнейшему изучению феномена языковой игры в рекламе. Полученные данные могут быть использованы в курсе лингвистического анализа рекламного текста, а также в других курсах, посвящённых рекламе.

Ключевые слова: языковая игра, рекламный дискурс, повтор, синтаксис, синтаксическая игра.

Постановка проблемы. В последние годы возрастает популярность исследования языковой игры в рекламном дискурсе. При создании языковой игры задействуются ресурсы всех языковых уровней. Синтаксис рекламного дискурса преследует цель привлечь внимание реципиента, заинтересовать его и в итоге заставить выбрать тот или иной товар или услугу. Но сделать это в условиях современной жизни нелегко, поэтому при создании рекламного текста копирайтеры стремятся (играть» не только со словами, но и с формой их подачи, так как синтаксические конструкции тоже могут иметь манипулятивный характер. $\mathrm{R}$ таким элементам синтаксического уровня относят использование про- 
стых предложений, т. к. «человек подсознательно склоняется к примитивным объяснениям сложных проблем, что приводит к использованию стереотипов» [5,c. 288], а реклама по своей сути “не терпит многословия и усложнённо-аморфных синтаксических оборотов, так как по своей природе должна быть динамичной») (должна призывать к действию) [1, с. 81-82]. Возможности синтаксиса широко используются и для образования комического эфффекта, целью которого является создание экспрессивного, запоминающего текста.

Постановка задач исследования. Целью данной статьи является рассмотрение приёмов языковой игры в рекламном дискурсе на синтаксическом уровне. Объектом исследования стала номинационная деятельность рекламиста при создании рекламного текста. Предметом исследования - приёмы языковой игры, применяемые на синтаксическом уровне рекламной коммуникации. В исследовании использованы описательный, количественный методы, метод компонентного анализа.

Ивложение основного материала. Трудно назвать синтаксическое явление, которое не подвергалось бы обыгрыванию. Чаще всего для создания языковой игры в рекламе задействованы: 1) парцелляция, 2) односоставные предложения, 3) синтаксический повтор, 4) антитеза, 5) неполные предложения. В данной статье подробнее остановимся на функционировании синтаксических повторов.

Повторение, по убеждению М. Жирмунского, “вызвано стремлением к усилению эмоциональной выразительности слова: отдельно взятое слово недостаточно сильно для того, чтобы передать всю напряжённость вложенного в него чувства» [4, с. 78]. Согласно И. Р. Гальперину, синтаксическое повторение включает в себя анафору, эпифору, анадиплосис, рамочную конструкцию и полисиндетон [3, с. 23$]$.

1. Анафора - стилистическая фигура, которая заключается в повторении начальных частей (звуков, слов, синтаксических или ритмических построений) смежных отрезков речи (слов, строк, строф, фраз). Этот приём позволяет акцентировать внимание на самом важном и придать рекламному тексту ритм и динамику, а также происходит программирование сознания потребителя:

«Пежо»: Сделано для удовольствия. Сделано для Вас.

С помощью анафоры может оригинально выделяться объект рекламы (в данном случае объектом является шампунь (Поляна»):

Шалпунь «Поляна»-с натуральными ингредиентами.

Шампунь "Поляна» - содержит пять иелебных трав.

Шалпунь «Поляна» - благотворно влияет на структуру волос.

Шампунь «Поляна» - и ваши волосы всегда прекрасны!

Такой повтор приводит к манипулированию сознанием реципиента, внедрению на подсознательном уровне наименования рекламируемого товара. Такой приём ещё именуется персеверацией [3, с. 244], это многократный повтор одинаковых сообщений в границах одного текста. В приведённом примере повторяется название шампуня, что приводит к непроизвольному запоминанию.

Каждый день очищает личо. Каждый день побеждает прыщи. (гель «Клерасил»). - Повтор темпорального детерминанта каждый день направлен на осознание потребителем необходимости ежедневного применения средства, приносящего пользу.

Гарлония с миром, гармония с собой! (реклама йогурта “Эрмигут»). - В данном рекламном тексте с помощью повтора существительного гарлония рекламист создаёт уверенность в том, что употребление данного продукта поможет человеку найти гармонию.

Вмир, где желание таниевать важнее, ием умение, в мир, где одна деталь меняет всё вокруг, в мир, где единственное "Да» важнее тысячи «Нет» (реклама “Кока-Колы»). - Рефреном звучащее имя существительное мир с предлогом в указывает на место. Следовательно, потенциальный покупатель понимает, что, попробовав данный напиток, очутится в нереальном, таинственном, загадочном мире мечты.

Нередко встречается анафора, образованная с помощью глагола в повелительном наклонении: Говорите, когда захочется, платите, когда удобно, говорите сейчас, платите потом! (мобильная связь (Мобилочка»). Императивная форма глагола создаёт побудительную интонацию. Автор рекламы призывает приобрести именно эту связь. Повтор слова (говорите) свидетельствует, что действие можно совершать неоднократно, поэтому данный вид товара становится выигрышным.

2. Эпифора - это повтор последнего элемента в нескольких высказываниях. Эпифора в большей степени, чем анафора, помогает создать определённый ритм. Чаще всего эпифорический повтор составляет марка продукта, благодаря чему на этом акцентируется внимание покупателей: Один paз — «ersil», всегда — «Persil» (реклама моющего средства “Persil»). Нередко эпифора образуется с помощью наречия: «Ариель»: не просто иисто, а безупречно иисто!» (реклама порошка “Ариель»). «Nokia»: ито красиво, то красиво!» (реклама мобильных телефонов “Nokia»).

Наречие несёт в себе оценочный характер и придаёт тексту краткость и выразительность, с помощью чего у потребителей создаётся позитивный настрой, положительное впечатление о товаре. Также для создания эпифоры используются иноязычные слова. Например: «Twix экстра», nопробуй әкстра! (реклама батончика “Тwix»). Иноязычные слова используются копирайтерами с целью придания новизны. Кроме того, в данном тексте употреблён глагол в побудительной форме.

Психологи считают, что целевые аудитории, менталитет которых сформирован тоталитарной идеологией, особенно восприимчивы к побудительным рекламным призывам [7, с. 78]. Например: 
ISSN 2307-4558; ISSN 2414-9489. Мова. 2017. № 28

Хотите чувствовать себя хорошо? - Артодиск. Хотите сбросить лет 20? - Артодиск. Хотите, как в молодости, радоваться жизни? - Артодиск (реклама фирмы "Артодиск»).

При помощи использования эпифоры можно также сымпровизировать своеобразный диалог между фирмой и её клиентом:

Буксировка с места аварии? - Да! Фирма "Гарант".

Ремонт в дороге? - Да! Фирма "Гарант".

Доступные чень? - Да! Фирма “Гарант” (реклама фирмы “Гарант»).

Диалог помогает воссоздать, проиграть конкретную ситуацию в нужном варианте. Так рекламистом создаётся готовый поведенческий образец. Это так называемое трансовое поведение, которое является гипнотической техникой и служит для "демонстрування готового поведінкового зразка, тобто в рекламному тексті показано поведінковий шаблон, певна реакція реагування при зіткненні з рекламованим товаром» [6, с. 108$]$.

3. Анадиплосис. Кроме термина (анадиплосис», существуют ещё термины (подхват» или "стык». Такого рода приём предполагает повтор слова или группы слов, заканчивающих отрезок речи, в начале следующего отрезка речи. Анадиплосис состоит в повторе слов на границах смежных отрезков. C помощью такого повтора выражается последовательность, причинная обусловленность, а также замедленный характер протекания. Например: Новая помада «Энергоблеск»: «Энергоблеск» на ваших губах (реклама губной помады “Энергоблеск»).

Повторяется ключевая фраза. Это заставляет покупателя обратить внимание на товар. Здесь анадиплосис осуществляет функцию композиционного стержня, за счёт чего реклама становится эфффективной: Слова. Слова нужны, жогда мы далеко (реклама сотовой связи “МТС»). Кроме приёма анадиплосиса, в данном тексте как приём языковой игры используется номинативное предложение. Выделяется слово "слова», поскольку для каждого человека общение - главное. Автор акцентирует внимание на том, что, даже находясь далеко друг от друга, мы можем общаться.

Bремя есть. Eсть «Mеллер» (реклама продукции “Меллер»). - В данном тексте анадиплосис образует глагол-инфинитив. Такой вид повтора безупречно демонстрирует последовательность и логичность. Стык создаёт также причинную обусловленность, то есть возможна замена: *Bремя есть, поэтому есть «Меллер».

В холодильнике негусто - не беда, ведь есть главное - есть майонез «Ласка». Майонез «Ласка» сделает любое блюдо вкуснее и изысканнее. Чтобы вы ни делали, делайте с «Лаской». Ласковый майонез «Ласка»! (реклама майонеза (Ласка»). Здесь анадиплосис - в наименовании рекламируемого продукта. Именно на этой фразе рекламист хотел сфокусировать внимание потенциальных покупателей, так как она является центральной. Повтор передаёт ощущение логичности.

4. Рамочная конструкция - элемент, повторяющийся в начале одного и в конце другого отрезка речи (такой повтор иногда называют кольцом). Это отрезок речи, который одинаково начинается и одинаково заканчивается: (1) «AOS» подходит для мытья даже детской посудъ. Для семьи я выбираю лучшее - «AOS» (реклама моющего средства "AOS»). При использовании приёма рамочной конструкции копирайтерами учитывается психологическое восприятие текста (так называемый (эфффект края»): психика человека создана так, что она "хорошо запоминает первое и последнее сообщение, и часто информация или эмоция, полученные первыми, будут долгое время корригировать всю следующую информацию о рекламном объекте» [2, с. 99]. (2) По-нашему, это шок! «ШШож» - это по-нашему!» (реклама батончика “Шок»). Кольцо передаёт замкнутое движение по кругу, (зацикленность) мысли на чем-либо. В первом примере - это моющее средство "AOS», во втором - наречие "по-нашему». Потенциальный покупатель сначала знакомится с предлагаемым продуктом, затем происходит закрепление информации в сознании. Во втором случае с помощью повтора модального слова и наречия по-нашему копирайтер "приближает» рекламируемый товар к потребителю. Выражается уверенность в том, что товар будет куплен.

Мои подруги продолжают пробовать разные антивозрастные кремы, а я остановилась на "Olay total effect»... «Olay total effect» - cекрет молодости и искренний совет подругам. Здесь намеренно повторяется слово подруга. В словаре Д. Н. Ушакова дано следующее толкование этого слова: “это девочка, девушка или женщина, с детских или с давних лет близко сдружившаяся с кемнибудь» [8, с. 678]. Используя это слово в начале и в конце рекламного текста, рекламист стремится стать ближе к адресатам, становится советчиком, другом, чтобы реципиент доверял ему, считая этот товар, действительно, эффективным.

Вкус майонеза «тr. Riссо-золотой» рождается в сочетании солнечной свежести молодых оливок и природной уникальности перепелиных яич... Майонез «тr. Ricсо-золотой» - богатство тонкого вкуса!» (реклама майонеза ("mr. Ricсо-золотой»). Автор выделяет слово вкус, так как рекламируется новый вкус майонеза. Подчёркивается, что не изменилось качество товара, изменился только вкус.

Использование повтора является важной и неотъемлемой составляющей многих рекламных текстов. Функции, которые выполняет данная конструкция в рекламном дискурсе, различны. Это может быть и усилительно-выделительная функция, когда повтор является средством усиления, выделения модального значения высказывания, например, значения актуализации внимания. Также важной 
является функция уточнения. C её помощью покупатель запоминает рекламу продукта, чтобы в дальнейшем использовать запомнившуюся информацию и быстро определиться с выбором. Для создания этой функции используется анафорический и эпифорический повтор. На наш взгляд, главная функция повторов в рекламном дискурсе - это функция создания ритмизации, а самым распространённым видом позиционного повтора является анафора.

Выводы. Таким образом, синтаксис рекламного дискурса является одним из важных аспектов языковой игры, так как организация, структура рекламного сообщения несёт огромную нагрузку при восприятии текста реципиентом. Используя разные возможности синтаксического строя языка, можно воздействовать на аудиторию, для которой предназначена реклама. Синтаксис рекламного текста способен повлиять на выбор потребителя и, в конечном итоге, способствовать продвижению продукта или услуги на рынке. Игра на синтаксическом уровне является яркой составляющей многих рекламных текстов. Такая игра базируется на использовании экспрессивного синтаксиса, целью которого является создание выразительности рекламного текста. Обычным стало мнение о том, что привлечь клиента или покупателя можно, в первую очередь, нарушением привычного и естественного. В синтаксисе это значит нарушение привычной структуры высказывания.

\section{Л и те ра тура}

1. Бернадская Ю. С. Текст в рекламе : учеб. пособие / Ю. С. Бернадская. - М. : ЮНИТИ-ДАНА, 2009. - 288 с. $228 \mathrm{c}$.

2. Викентьев И. Л. Приёмы рекламы и Public Relation / И. Л. Викентьев. - К. : Бизнес-пресса, 1997. - Ч. I. -

3. Гальперин И. Р. Текст как объект лингвистического исследования / И. Р. Гальперин. - М. : Изд-во литературы на иностр. языках, $1981 .-276$ с.

4. Жирмунский В. М. Теория литературы. Поэтика. Стилистика / В. М. Жирмунский. - Л. : Наука, 1977. 199 c.

5. Кара-Мурза С. Г. Манипуляция сознанием / С. Г. Кара-Мурза. - М. : ЭКСМО-Пресс, 2002. - 832 с.

6. Кутуза H. В. Прийоми мовної гри як мнемонічні техніки та ай-стопери рекламного тексту / Н. В. Кутуза // Реклама та PR у масовому інформаційному просторі. - Одеса : Астропринт, 2009. - C. 107-115.

7. Пешковский A. M. Русский синтаксис в научном освещении / А. М. Пешковский. - М. : Языки славянской культуры, 2001. - 510 с.

8. Ушаков Д. Н. Большой толковый словарь современного русского языка / Д. Н. Ушаков. - М. : Альта-Принт, 2009. $-1248 \mathrm{c}$.

\section{References}

1. Bernadskaya, Yu. S. (2009), The text in advertizing : A training manual for university students [Tekst $v$ reklame : ucheb. posobije dlia studentov vuzov], UNITY-DANA, Moscow, $288 \mathrm{p}$.

2. Vikentyev, I. L. (1997), Methods of advertizing and Public Relation [Prijomy reklamy $i$ Public Relation], Business press, Kiev, part 1, 228 p.

3. Galperin, I. R. (1981), Text as object of a linguistic research [Tekst kak objekt lingvisticheskogo issledovanija], Publishing house of literature in foreign languages, Moscow, $276 \mathrm{p}$.

4. Zhirmunsky, V. M. (1977), Theory of literature. Poetics. Stylistics [Teorija literatury. Poetika. Stilistika], Nauka, Leningrad, $199 \mathrm{p}$.

5. Kara-Murza, S. G. (2002), Manipulation with consciousness [Manipuljatsija soznaniem], EKSMO-Press, Moscow, $832 \mathrm{p}$.

6. Kutuza, N. V. (2009), "The receptions of the language game as mnemonic techniques and Ai-stoppers of the advertising text", Advertising and PR in the mass media ["Pryjomy movnoï gry jak mnemonichni tekhníky ta aj-stopery reklamnogo tekstu", Reklama ta PR u masovomu informacijnomu prostori], Astroprynt, Odessa, pp. 107-115.

7. Peshkovsky, A. M. (2001), The Russian syntax in scientific visibility [Russkiy sintaksis v nauchnom osveshchenii], Languages of Slavic culture, Moscow, 510 p.

8. Ushakov, D. N. Big dictionary with definitions of modern Russian [Bol'shoj tolkovyj slovar' sovremennogo russkogo jazyka], Alta-Print, Moscow, 1248 p.

\section{СоБЧЕНКо Наталія Сергї̈вна,}

старший викладач кафедри російської мови Одеського національного університету імені І. І. Мечникова; Французький бульвар, 24/26, м. Одеса, 65058, Україна; тел.: +38 0679461358 ;

e-mail: ecoletk17@ukr.net; ORCID ID: 0000-0002-1382-5058

\section{ПРИЙОМИ СИНТАКСИЧНОЇ ГРИ В РЕКЛАМНОМУ ДИСКУРСІ УКРАЇНИ}

Анотація. Мета статті - розглянути прийоми мовної гри в рекламному дискурсі на синтаксичному рівні. Об'є大т дослідження - номінаційна діяльність в рекламному дискурсі. Предмет дослідження - прийоми мовної гри на синтаксичному рівні. У статті використано наступні методи: описовий, кількісний, метод компонентного аналізу. Результат дослідження: виокремлено основні прийоми мовної гри на синтаксичному рівні, докладно розглянуто прийом синтаксичного повтору. Визначено основну функцію використання мовної гри на синтаксичному рівні в рекламі. 
Висновки. Гра на синтаксичному рівні є яскравою складовою багатьох рекламних текстів. Найчастіше для створення мовної гри в рекламі застосовано такі прийоми: парцеляцію, предикативну односкладність, повтор, антитезу, неповноту висловлювання. Найчастотнішим є синтаксичний повтор, який має багато різновидів: анафоричний, епіфоричний, анадіпловісний, повтор у рамковій конструкції, полісіндетон. Результати роботи можуть бути застосовані у подальшому вивченні феномену мовної гри в рекламі, використані в курсі лінгвістичного аналізу рекламного тексту, в інших курсах, що спрямовані на вивчення рекламного дискурсу та рекламної справи.

Ключові слова: мовна гра, рекламний дискурс, повтор, синтаксис, синтаксична гра.

Natalia S. SOBCHENKO,

senior teacher of Russian Language Department of the Odessa I. I. Mechnikov National University; 24/26, Frantsuzskij blvd., Odessa, 65058, Ukraine; ph.: +38 0679461358 ; e-mail: ecoletk17@ukr.net; ORCID ID: $0000-0002-1382-5058$

\section{RECEPTIONS OF THE SYNTACTIC GAME IN THE ADVERTISING DISCOURSE OF UKRAINE}

Summary. The purpose of article is to consider methods of creation of a language game in an advertizing discourse at the syntactic level. An object of research is nomination activity in advertizing discourse. The subject of research is the methods of creation of a language game at the syntactic level of the language. In the article the following methods are used: descriptive, quantitative, method of the component analysis. Result of the research: the main methods of creation of a language game at the syntactic level are called and reception of syntactic repetition is in detail considered. The main function of use of a language game at the syntactic level in advertizing is defined. Conclusions. A game at the syntactic level is a bright component of many advertizing texts. Most often for creation of a language game the following receptions are involved in advertizing: parceling, one-member sentences, syntactic repetition, antithesis, incomplete sentences. The most frequency is syntactic repetition which includes an anaphora, to an epifor, anadiplosis, a frame design and polisindenton. Practical use of results of the research is that it results promote further studying of a language game in advertizing, could be applied when studying the linguistic analysis of the advertizing text and also can be used in special courses devoted to advertizing.

Key words: language game, advertizing discourse, iteration, syntax, syntactic game.

Статтю отримано 30.09.2017 p.

http://dx.doi.org/10.18524/2307-4558.2017.28.115857

УДК 811.161.1'282'373.74:004.823

СТЕПАНОВ Евгений Николаевич,

доктор филологических наук, заведующий кафедрой русского языка

Одесского национального университета имени И. И. Мечникова;

Французский бульвар, 24/26, г. Одесса, 65058, Украина; тел.: +38 0964966406;

e-mail: rus_lang@onu.edu.ua; ORCID ID: 0000-0002-5441-9822; SPIN-код 8665-0882

\section{СЦЕНАРНАЯ СПЕЦИФИКА РЕГИОНАЛЬНОЙ ФРАЗЕОЛОГИИ}

Аннотация. Цель данной работы - определить черты, общие для фразеологических единиц, которые возникают на основе местных / региональных сценариев и функционируют в территориально ограниченных локусах распространения русского языка. Кроме того, автор сделал попытку установить зависимость прецедентности фразеологизма от хронотопа как закономерной связи пространственно-временных координат, а также охарактеризовать особенности функционирования местных фразеологизмов в локусах, разных по признаку доминирующего в них социального и / или профессионального статуса русскоговорящего населения: в городе и селе. Объектом изучения стали региональные фразеологические единицы, субъектом - региональные сценарии, порождающие прецедентные феномены, которые дают начало фразеологизации содержащих их единиц. Результатом данного исследования стало установление таких основных черт региональных фразеологизмов: территориальная ограниченность функционирования; трудности понимания значения носителями русского языка как родного, проживающими в других регионах; способность распространяться на другие территории и входить в общенациональный русский язык. Выводы указывают на непосредственную связь понятия прецедентного феномена в лингвистике с понятиями доминанты и хронотопа. С изменением доминанты восприятия процесса, действия, предмета, признака рождаются предпосылки к возникновению новых прецедентных феноменов и устареванию уже существующих. По мере распространения ПФ в коммуникативном пространстве искажаются сценарии их возникновения и стирается зависимость их функционирования от первичных сценариев. Проходя рубеж этой зависимости, фразеологизм как лингвосемиотический феномен синхронизируется в речи, теряет связь с прошлыми сценариями и ориентируется на семантическую сочетаемость в том или ином дискурсе.

Ключевые слова: региональный фразеологизм, прецедентный сценарий, прецедентный феномен, русская речь, городская речь, диалект, лингвокультурный. 